\title{
Trabalho do enfermeiro com adolescentes nas estratégias saúde da família: desenvolvimento de ações educativas
}

\author{
Nurses 'work with adolescents in family health strategies: \\ development of educational actions
}

\author{
Elisabeta Albertina Nietsche' $\bullet$ Cléton Salbego ${ }^{2} \bullet$ Larice Gonçalves Terra $^{3} \bullet$ Andressa Böck $^{4}$ \\ Joseph Wrague da Conceição ${ }^{5}$ Silvana Bastos Cogo ${ }^{6}$
}

\begin{abstract}
RESUMO
Objetivo: conhecer como são desenvolvidas as ações educativas voltadas aos adolescentes no contexto de trabalho do enfermeiro nas Estratégias Saúde da Família. Método: pesquisa qualitativa, descritiva-exploratória desenvolvida com 10 enfermeiros de Estratégias Saúde da Família. A coleta dos dados ocorreu no mês de maio de 20I5, por meio de entrevista semiestruturada. Os dados foram analisados a luz da análise de conteúdo. Resultados: emergiram duas categorias de análise, sendo, o desenvolvimento das ações educativas pela equipe de saúde da família; dificuldades no desenvolvimento das ações educativas. Conclusão: percebe-se que as ações educativas são desenvolvidas em coletividade, desde o planejamento e execução, na maioria das unidades de saúde, e nos locais onde isso não ocorre, os enfermeiros compreendem a necessidade de iniciar um trabalho em equipe. $O$ enfermeiro é percebido como responsável por coordenar a equipe, e orientar o processo de preparação das ações educativas.

Descritores: Estratégia saúde da família; Adolescente; Educação em saúde; Cuidados de Enfermagem; Enfermeiras de Saúde da Família
\end{abstract}

\begin{abstract}
Objective: to know how educational actions are developed for adolescents in the context of nurses' work in Family Health Strategies. Method: qualitative, descriptive-exploratory research developed with 10 nurses from Family Health Strategies. Data collection took place in May 20I5, through semi-structured interviews. The data were analyzed in the light of content analysis. Results:

two categories of analysis emerged, namely, the development of educational actions by the family health team; difficulties in the development of educational actions. Conclusion: it is noticed that educational actions are developed collectively, from planning and execution, in most health units, and in places where this does not occur, nurses understand the need to start teamwork. The nurse is perceived as responsible for coordinating the team, and guiding the process of preparing educational actions.
\end{abstract}

Keywords: Family Health Strategy;Adolescent; Health Education; Nursing Care; Family Nurse Practitioners

NOTA

I Graduação em Enfermagem e Obstetrícia pela Faculdade Nossa Senhora Medianeira. Doutora em Enfermagem pela Universidade Federal de Santa Catarina. Docente do Departamento de Enfermagem da Universidade Federal de Santa Maria. ORCID: https://orcid.org/0000-0002-8006-2038

2 Graduação em Enfermagem pela Universidade Regional Integrada do Alto Uruguai e das Missões - URI Campus Santiago. Mestre em Enfermagem pela Universidade Federal de Santa Maria. Docente Faculdade do Sistema de Ensino Gaúcho - FaSEG. ORCID: https://orcid.org/0000-0003-3734-9970

3 Graduação em Enfermagem pela Universidade Federal de Santa Maria. Mestre em Enfermagem pela Universidade Federal de Santa Maria. ORCID: https://orcid. org/0000-000I-77I9-3865

4 Graduação em Enfermagem pela Universidade Federal de Santa Maria. Mestre em enfermagem pela Universidade Federal de Santa Maria. https://orcid.org/00000002-9423-5I55

5 Acadêmico de Enfermagem pela Universidade Federal de Santa Maria. https://orcid.org/0000-0002-49I5-3724

6 Graduação em Enfermagem pelo Centro Universitário Franciscano. Doutora em Enfermagem pela Universidade Federal do Rio Grande. Docente do Departamento de Enfermagem da Universidade Federal de Santa Maria. ORCID: https://orcid.org/0000-0002-1686-8459 


\section{INTRODUÇÃO}

A adolescência é historicamente construída a partir de critérios múltiplos que abrangem as dimensões biopsicológica, cronológica e social. Ser adolescente é viver uma fase em que múltiplas mudanças acontecem e se refletem no corpo físico, aumentando as habilidades psicomotoras e a atuação dos hormônios, o que provoca mudanças radicais de forma e expressão.(') Os critérios cronológicos da adolescência são definidos pelo Estatuto da Criança e do Adolescente (ECA) como aqueles entre 12 e 18 anos de idade. ${ }^{(2)}$

As condições dos adolescentes brasileiros chamam a atenção com números expressivos de mortes por causas externas, gravidez precoce, abortos, alto índice de desemprego, infecção por doenças sexualmente transmissíveis, evasão escolar e envolvimento com drogas e violência. Estes fatores de vulnerabilidade e risco podem ser influenciados por baixas condições sociais e econômicas, pelas falhas no sistema educacional, por serviços de saúde precários e, de forma multifacetada, pelo entorno social fragilizado. A noção de vulnerabilidade em determinada situação é fundamental, já que pode contribuir para renovar as práticas de saúde coletiva, nas quais o cuidado às pessoas deve ser multidisciplinar. ${ }^{(3)}$

Para dar conta da demanda voltada ao adolescente, a implantação de programas de atendimento específico ao adolescente, composto por uma equipe multiprofissional especializada, são estratégias de ação para a manutenção da saúde da população atendida. $O$ enfermeiro enquanto membro da equipe, possui o papel de educador, o qual deve abordar as informações passadas ao adolescente de forma que a realidade do sujeito seja levada em consideração para obter um cuidado de qualidade. ${ }^{(4)}$

Assim, a educação em saúde vincula $\circ$ alcance de conhecimentos e habilidades básicas com o senso de identidade, autonomia, solidariedade e responsabilidade dos indivíduos por sua própria saúde e a da comunidade, compondo saberes, aptidões e atitudes, proporcionando informações de qualidade sobre o bem-estar. ${ }^{(5)}$

$O$ adolescente, que vivencia um momento de vulnerabilidades e mudanças, necessita de um atendimento especial, em relação à sua saúde, para que possa desenvolver sua autonomia para tomar decisões saudáveis. Assim, espera-se que os resultados desse estudo contribuam para a educação em saúde junto aos adolescentes, propondo modelos assistenciais que contemplem um olhar diferenciado em relação a essa fase de desenvolvimento humano.

Face ao exposto, é percebido o papel fundamental da equipe de saúde da família na Estratégia Saúde da Família (ESF), no que tange desenvolver ações educativas em saúde que contemplem os adolescentes. $O$ impacto de ações mais efetivas e a busca pelo envolvimento cada vez maior desta parcela da comunidade nas ações básicas de saúde desprendem como possibilidade contribuir para a prevenção de inúmeros danos, com repercussões não somente restritas aos indivíduos atendidos, mas voltadas à comunidade na qual estes estão inseridos. Desta forma, ações positivas e planejadas, conduzidas adequadamente nesta fase de vulnerabilidade do ser humano, podem contribuir, efetivamente, para a formação de cidadãos mais preparados para o futuro. Neste contexto, o enfermeiro e sua equipe saúde da família, em função de sua capacidade de inserção nas comunidades atendidas, constituem-se em um instrumento poderoso para a atuação direta junto ao adolescente.

Frente ao apresentado, questiona-se "como as ações educativas voltadas aos adolescentes são desenvolvidas no contexto de trabalho do enfermeiro nas Estratégias Saúde da Família (ESF) de um município da região centro do estado do Rio Grande do Sul? E como objetivo: conhecer como são desenvolvidas as ações educativas voltadas aos adolescentes no contexto de trabalho do enfermeiro nas Estratégias Saúde da Família.

\section{MÉTODOS}

Trata-se de uma pesquisa de abordagem qualitativa, do tipo descritiva e exploratória. O município onde a pesquisa foi desenvolvida possui 14 unidades de ESF, localizadas na área urbana e rural as quais totalizam 16 equipes de saúde. Vale salientar que duas unidades possuem equipe dobrada devido a área de abrangência e número de famílias cadastradas. Cada equipe é composta por um médico, um enfermeiro, um técnico em enfermagem e agentes comunitários de saúde (ACS).

Cabe destacar que as ESF realizam atendimentos à população de todas as faixas etárias e realizam diferentes atividades grupais, semanalmente, para auxiliar na assistência, tais como os grupos de idosos, de hipertensos e diabéticos, de gestantes. No entanto, quando se tratam de adolescentes, este número é reduzido.

Para a seleção dos participantes, foram utilizados, como critérios de inclusão: ser enfermeiro e, atuar no mínimo a um ano no serviço devido à necessidade de conhecimento da população atendida em sua unidade. Como critérios de exclusão: estar em laudo, atestado, férias ou qualquer forma de afastamento.

Dos 16 enfermeiros atuantes nas 14 ESF's, dois estavam vinculados ao serviço a menos de um ano, uma estava em licença saúde e, três recusaram-se a participar do estudo sem especificar motivo da negativa. Frente ao exposto, participaram desta investigação 10 enfermeiros.

A coleta de dados foi realizada pela pesquisadora no mês de maio de 2015, nas dependências das ESF conforme disponibilidade dos enfermeiros, em datas e horários previamente escolhidos por eles, em espaços que manti- 
vessem sigilo e confidencialidade, participando assim apenas a pesquisadora e o participante. Utilizou-se a técnica da entrevista semiestruturada, a qual a pesquisadora já possuía experiência através da participação de colaboração em outras pesquisas. As questões que versavam sobre definição, realização e importância das ações educativas e os cenários em que eram desenvolvidas. $O$ guia de entrevista utilizado na presente pesquisa passou pelo teste piloto, e não necessitou de adequações.

As entrevistas foram gravadas em áudio com auxílio de equipamento portátil, sendo transcritas e, registradas em códigos alfanuméricos (EI, E2...EI0), não foram necessárias repetições das mesmas e estas não retornaram aos participantes para comentários e/ou correções. A duração das entrevistas variou entre 37 minutos e uma hora e 22 minutos. Ainda, a pesquisadora utilizou um diário para registrar aspectos relevantes das entrevistas que foram julgadas importantes pela pesquisadora. Não foi utilizado o critério de saturação de dados.

Após, foram analisadas conforme a análise de conteúdo temática de $\operatorname{Bardin}^{(6)}$ que se concentra em três polos: pré-análise e exploração do material, mediante leituras e organização dos achados visando identificar as unidades de significação que respondessem ao objeto em estudo, atendendo aos seguintes critérios: exaustividade, representatividade, homogeneidade, pertinência e exclusividade. Por fim, houve tratamento e interpretação dos dados, com base na literatura específica, o que permitiu a construção de duas categorias analíticas, descritas na seção "resultados".

Ressalta-se que os princípios éticos foram respeitados, de acordo com a Resolução n. 466/I2 $2^{(7)}$, do Conselho Nacional de Saúde. O estudo foi aprovado pelo Comitê de Ética em Pesquisa da Universidade Federal de Santa Maria (UFSM), sob CAAE: 403483 I 4.7.0000.5346.

\section{RESULTADOS}

O corpus da pesquisa foi composto por 10 enfermeiros, sendo oito mulheres e dois homens. $O$ tempo de atuação dos enfermeiros variou entre três a 14 anos, sendo que oito participantes apresentaram tempo de atuação na enfermagem que variou entre um a 10 anos e, dois com atuação entre II e I4 anos na área. Nesse sentido, emergiram duas categorias: o desenvolvimento das ações educativas pela equipe da ESF; dificuldades no desenvolvimento das ações educativas.

\section{O desenvolvimento das ações educativas pela equipe da Estratégia Saúde da Família}

A partir dos relatos dos participantes percebeu-se que as demandas de atendimento aos adolescentes, nas unidades, são diferenciadas. Porém, a fragilidade se inicia com aqueles que, mesmo confirmando atender aos adolescentes, apontam a não utilização de uma agenda específica para essa população:

[...] a gente até atende, só que não são muitos. Por isso nem temos agenda para o adolescente (E2).

[...] nós atendemos muitos adolescentes aqui na unidade. Não temos agenda para o adolescente, ele marca consulta na agenda do adulto (E4).

[...] a gente atende bastante adolescentes. Eles são incluídos dentro da agenda das crianças ou dos adultos, depende das vagas que têm no momento que eles procuram (E7).

[...] atendemos muitos. Não temos agenda para o adolescente, mas eles entram na agenda do adulto (E9).

Em relação ao desenvolvimento do trabalho em equipe, constatou-se uma dicotomia, em que, algumas ESF desenvolvem o trabalho coletivo e outras não realizam. Além disso, verificou-se que o enfermeiro tem o papel de líder no desenvolvimento do trabalho em equipe:

[...] a equipe toda ajuda, tanto é que eles me trouxeram que seria interessante trabalhar com os adolescentes (E2).

[...] toda equipe opina, todos participam do planejamento e execução, enquanto equipe (E3). [...] por enquanto a equipe não tem trabalhado junto nessas ações, mais é a enfermeira (E8).

[...] nas ações com os adolescentes é praticamente só a enfermagem, mesmo, a enfermeira e a técnica em enfermagem (E4).

[...] o enfermeiro tem que organizar, tem que ter paciência, tem que chamar a equipe para trabalhar junto nessas ações, porque a equipe não trabalhando junto, não tem um trabalho legal, efetivo (E4).

[...] a gente, enquanto enfermeiro tem o papel de estar chamando, organizando, coordenando essas ações e, junto com a equipe estar propondo estratégias para melhorar essas ações na população (E7).

O ACS, integrante da equipe da ESF, foi evidenciado como membro participativo e ativo nas ações voltadas aos adolescentes:

[...] vou esperar os agentes comunitários de saúde voltarem de férias para a gente conversar e decidir qual atividade a gente pode fazer (E2).

[...] baseado nas observações dos agentes comunitários posso avaliar o que deve ser falado nas ações educativas. $E$ se tu não envolver $o$ agente de saúde que está lá na casa do adolescente todo dia, não tem como tu saber as 
necessidades, o que acontece nas casas, nas familias (E4).

\section{Dificuldades no desenvolvimento das ações educativas}

As dificuldades vivenciadas pelos enfermeiros foram: formação acadêmica fragilizada ao não preparar profissionalmente para o atendimento aos adolescentes; falta de recursos humanos e materiais nas ESF; falta de apoio institucional; falta de cursos de atualizações e capacitações para trabalharem com os adolescentes. Contudo, os enfermeiros também enfatizaram que o vínculo e o convívio com a comunidade é o essencial para realizar uma atividade com sucesso:

[...] a minha formação me preparou muito pouco para trabalhar com adolescentes. A gente teve uma aula teórica e na prática muito pouco, então, a gente aprende mesmo é na prática profissional, meio a força, com o tempo (E4).

[...] acredito que a gente precisaria de maiores espaços dentro até mesmo do serviço, dentro da secretaria municipal de saúde, para poder conseguir fazer ações de educação permanente e continuada, por meio de capacitações (E5). [...] a gente não consegue chegar até os adolescentes porque a ESF fica muito longe (E6).

[...] às vezes é a falta de um apoio institucional, da prefeitura, que às vezes a gente quer trabaIhar alguma coisa, mas depois a gente não vê apoio (E8).

[...] faltam conteúdos referente aos adolescentes, durante a formação. Somente a base é dada. Apesar disso, é ilusão tu achar que vai sair da graduação, de uma pós graduação, de um mestrado pronto para qualquer coisa, porque não vai, você vai sair com a base, e é você quem tem que buscar através desse vínculo, desse convívio, se tu não conhecer a comunidade que tu vai trabalhar, tu não vai conseguir, tu não vai ter sucesso (EIO).

\section{DISCUSSÃO}

A assistência à saúde do adolescente deve respeitar suas particularidades e necessidades, face as transformações físicas e psicológicas inerentes a faixa etária. Para tanto, as ESF, precisam elaborar e desenvolver ações, a fim de repercutir nos hábitos de vida, promoção da saúde e prevenção de agravos. Na presente pesquisa, as ESF prestavam atendimento aos adolescentes, porém com ausência de agenda específica, ou seja, a demanda, incluíase, no agendamento dos adultos, ou das crianças. Neste sentido, parece haver uma fragilidade, ao desconsiderar as peculiaridades no cuidado aos adolescentes, partindo do pressuposto de ausência de um processo de direcionamento da assistência.

Sob essa perspectiva, a ESF, instituída em 2006, é considerada estratégia prioritária de estruturação da atenção básica e a principal porta de entrada do Sistema Único de Saúde (SUS). Este serviço é o primeiro contato, na longitudinalidade e na coordenação do cuidado. ${ }^{(8)}$ $\mathrm{Na}$ prática de uma assistência integral a equipe de saúde deve pensar, planejar e executar ações aos adolescentes, no intuito de produzir resultados satisfatórios.As atividades privativas do enfermeiro incluem o planejamento, organização, coordenação, execução e a avaliação dos serviços de assistência de enfermagem..$^{(9)}$ Assim, o trabalho em equipe exige que o enfermeiro considere cada indivíduo em sua totalidade, respeitando as individualidades, reconhecendo e fomentando competências, capacidades e potencialidades de cada membro da equipe.Além disso, é importante que, durante o trabalho diário, o enfermeiro forneça oportunidades de participação, procurando ouvir as opiniões dos membros da equipe.

Os resultados da pesquisa, apontaram sobre a importância do enfermeiro coordenar e liderar a equipe de saúde, para o desenvolvimento de ações educativas aos adolescentes, com vistas ao trabalho coletivo e propondo alterações nas estratégias de trabalho, a fim de aprimorar a assistência aos adolescentes. Entretanto, há uma necessidade de incluir os membros da equipe, pois por vezes, o enfermeiro considera conveniente, ágil e tranquilo desenvolver ações educativas sem envolver a equipe, justamente pela necessidade de flexibilidade de cada um, que na maioria das vezes, é o que dificulta o trabalho coletivo. Assim, o enfermeiro opta por realizar as atividades de modo solitário.

Cabe destacar que, além das competências gerais, os enfermeiros têm competências específicas, como a de negociação, de gerenciamento de conflitos, de pessoas, de materiais, de tempo, de informações e o do trabalho em equipe. ${ }^{(10)}$ Nesse sentido, as atividades desempenhadas conjuntamente entre os diferentes profissionais, não se apresenta como tarefa fácil, pois cada membro visualiza a pessoa com necessidades distintas, que somadas constituem uma visão ampliada. Além disso, nas ações com os adolescentes, esse trabalho é imprescindível, pois há necessidade de criação de estratégias criativas para obtenção de resultados que supram as demandas apresentadas.

É válido mencionar, sobre a importância da construção em equipe de um projeto, em que haja complementaridade entre os trabalhos dos diferentes profissionais, bem como a interação entre os trabalhadores e destes com os usuários, conforme apontado nos resultados da pesquisa. Aspectos, estes relacionados ao campo das relações entre os profissionais, como o respeito, a exis- 
tência de conflitos, a organização das atividades, rotinas e procedimentos, a liberdade, o prazer e a autonomia na organização do processo de trabalho, o estímulo à participação da comunidade e a garantia de criação de vínculos, laços, corresponsabilização e acolhimento.(II) Assim, as ações em equipe é uma modalidade coletiva, caracterizada pela relação recíproca entre as dimensões complementares de trabalho e interação. ${ }^{(12)}$

Os enfermeiros, também destacaram o planejamento das ações educativas com base nas informações dos ACS, pois estes complementam informações sobre a saúde do adolescente, em virtude das visitas diárias e conhecimento do contexto familiar, e por isso devem ser atuantes nas ações educativas. Destaca-se ainda, que a complementariedade de conhecimentos, oriundas de campos especializados de atuação, repercutem no cuidado integral. Nesse sentido, a ação em equipe pressupõe a possibilidade da prática de um profissional se (re) construir na prática do outro, transformando a intervenção na realidade em que estão inseridos. Contudo, o desafio parece estar no desenvolvimento de um trabalho em equipe, pois configura-se como uma tarefa que requer uma construção diária, reconhecimento das potencialidade e fragilidades cotidianas, a fim de se perceberem enquanto membro de uma equipe.

Sobre o preparo, abordagem profissional e as ações educativas destinadas aos adolescentes, constatou-se que, durante a graduação, é oferecida de maneira reduzida no período de formação. Sob essa perspectiva, há necessidade, conforme constatado nessa pesquisa de buscar treinamentos especializados, a fim de garantir uma atuação qualificada. Uma concepção educativa relacionada a processos de ensino aprendizagem crítico-reflexivos, durante a formação, propõe a incorporação de situações de ensino que provoquem uma aproximação crítica do aluno com a realidade, a qual deve ser capaz de levá-lo à reflexão sobre problemas que geram curiosidade e desafio, ocorrendo também a disponibilização de recursos para pesquisar necessidades e buscar novas soluções. ${ }^{(13)}$

Há que se destacar, que houveram manifestações dos enfermeiros sobre as fragilidades dos serviços, relacionadas a deficiência de recursos humanos e materiais, incluindo a retirada de recursos financeiros próprios para custear as ações e estratégias educativas (folders, cartazes, fantoches), e a demanda do território de abrangência, que por vezes dificultaram o acesso dos enfermeiros aos adolescentes. Neste sentido, os aspectos estruturais, a disponibilidade e $\mathrm{o}$ acesso a recursos materiais, são fatores que dificultam o trabalho do enfermeiro, influenciando suas atividades cotidianas e distanciando este profissional de sua essência, o cuidado. ${ }^{(14)}$
Complementa-se, também que houve manifestações relacionadas a dificuldade da instituição de saúde respaldar e atuar no incentivo ao desenvolvimento da assistência em saúde aos adolescentes. Neste sentido, ○ apoio institucional é uma função que reformula o modo tradicional de se fazer coordenação, planejamento, supervisão e avaliação em saúde. É uma função de fomento e acompanhamento de processos de mudança nas organizações, misturando e articulando conceitos e tecnologias advindas da análise institucional para pensar a gestão. É tarefa primordial do apoio a oferta de suporte ao movimento de mudança, buscando fortalecê-los no próprio exercício da produção de sujeitos em seus processos de mudanças. ${ }^{(15)}$

Os resultados desse estudo apresentam como limitação o desenvolvimento em dez ESF da região central do Rio Grande do Sul, cujas vivências e experiências de enfermeiros podem diferir de outras ESF e outras regiões e Estados.

\section{CONCLUSÃO}

As ações educativas voltadas aos adolescentes, no contexto de trabalho do enfermeiro, são desenvolvidas em coletividade, desde o planejamento e execução, na maioria das ESF, e nos locais onde isso não ocorre, os enfermeiros compreendem a necessidade de iniciar um trabalho em equipe. Nesse sentido, também foi evidenciado que o enfermeiro é o profissional que se responsabiliza por coordenar a equipe, e orientar o processo de preparação das ações educativas.

Outros aspectos destacados foram a carência teórica sobre adolescentes na formação profissional, além da falta de apoio institucional, no que se refere a cursos de capacitações, falta de recursos humanos e materiais, os quais prejudicam a assistência profissional. Nesse sentido, salienta-se a necessidade de os gestores ofertarem suporte para as equipes das ESF no que se refere aos recursos humanos e materiais. Ademais, o desenvolvimento de cursos de atualização e capacitação para que os profissionais sintam-se preparados para trabalhar com o público adolescente.

Espera-se que este estudo contribua para fomentar ações educativas direcionadas ao público adolescente no âmbito da atenção primária, estimular os enfermeiros quanto à prática assistencial direcionada a essa população, apontar necessidades curriculares na graduação em enfermagem; corroborar para o âmbito da pesquisa, ensino e extensão a fim de reduzir as vulnerabilidades sociais vivenciadas pelos adolescentes. Os resultados desse estudo apresentam como limitação o desenvolvimento em dez ESF da região central do Rio Grande do Sul, cujas vivências e experiências de enfermeiros podem diferir de outras ESF e outras regiões. 


\section{REFERÊNCIAS}

I. Ferreira MA, Alvim NAT, Teixeira MLO, Veloso RC. Saberes de adolescentes: estilo de vida e cuidado à saúde. Texto Contexto Enferm [Internet]. 2007 [acesso em 2017 mar 2I];16(2):217-24. Disponível em: http://www.scielo. br/scielo.php?pid=S0 104-07072007000200002\&script=sci_abstract\&tlng=pt doi: http://dx.doi.org/I0.I590/S0 I0407072007000200002

2. Lei n. 8069, de 13 de jul. de 1990 (BR). Estatuto da Criança e do Adolescente, Brasília, DF, jul 1990. Disponível em: http:// www.planalto.gov.br/ccivil_03/LEIS/L8069.htm.

3. Sánchez AIM, Bertolozzi MR. Pode o conceito de vulnerabilidade apoiar a construção do conhecimento em Saúde Coletiva?. Ciênc. saúde coletiva [Internet]. 2007 [acesso em 2017 abr I5];12(2):319-24. Disponível em: http://www.scielo.br/scielo.php?script=sci_arttext\&pid=S|4|3-8| 232007000200007 doi: http://dx.doi. org/|0.1590/S|4|3-8|232007000200007.

4. Salum GB, Monteiro LAS. Educação em saúde para adolescentes na escola: um relato de experiência. Rev Min Enferm [Internet]. 2015 [acesso em 2017 abr I3]; I9(2):246-5 I.Disponível em: http://www.reme.org.br/artigo/detalhes/1019 doi: http://dx.doi.org/ 10.5935//415-2762.20150039.

5. Tinoco VA, Reis MMT, Freitas LN. O enfermeiro promovendo saúde como educador escolar: atuando em primeiros socorros. Revista Transformar [Internet]. 2014 [acesso em 2017 mai 20];06: I04-I3. Disponível em: http://www.fsj.edu. br/transformar/index.php/transformar/article/view/I6/I5.

6. Bardin L. Análise de conteúdo. $3^{\mathrm{a}}$ reimpressão da $\mathrm{I}^{\mathrm{a}}$ edição de 2016. São Paulo:Edições 70, 2016.

7. Resolução $N^{\circ} 466$ do Conselho Nacional de Saúde, de 12 de dezembro de 2012 (BR) [Internet]. Aprova as diretrizes e normas regulamentadoras de pesquisas envolvendo seres humanos. Diário Oficial da União. 12 dez 2012 [acesso em: 02 fev 20l8]. Disponível em: http://bvsms.saude.gov.br/bvs/ saudelegis/cns/2013/res0466_12_12_2012.html.

8. Malta DC, Santos MAS, Stopa SR, Vieira JEB, Melo EA, Dos Reis AAC. A Cobertura da Estratégia de Saúde da Família (ESF) no Brasil, segundo a Pesquisa Nacional de Saúde, 2013. Ciênc. saúde coletiva [Internet]. 2016 [acesso em $2018 \mathrm{fev}$ I2];2I(2): 327-38. Disponível em: http://www.scielo.br/scielo.php?pid=s | 4 | 3=8 | 2320 | 6000200327-\&scriptsci_abstract\&tlng=pt doi: http://dx.doi.org//0.1590//4/381232015212.23602015 .
9. Decreto $n^{\circ}$ 94.406, de 8 de junho de 1987 (BR) [Internet]. Regulamenta a Lei $n^{\circ} 7.498$, de 25 de junho de 1986, que dispõe sobre o exercício da enfermagem, e dá outras providências. 25 jun 1986 [acesso em 05 mar 2018]. Disponível em: http://www.planalto.gov.br/ccivil_03/decreto/I980-1989/d94406.htm.

10. De Paula M, Peres AM, Bernardino E, Eduardo EA, Sade PMC, Larocca LM. Características do processo de trabalho do enfermeiro da estratégia de saúde da família. Rev Min Enferm [Internet]. 2014 [acesso em 03 mar 20I8]; I8(2): 45462. Disponível em: http://reme.org.br/artigo/detalhes/939 doi: http://www.dx.doi.org// 0.5935//4 I5-2762.20 I 40034.

I I. Garcia ACP, Lima RCD, Freitas PSS, Fachetti T, Cola JP, Andrade MAC. $O$ trabalho em equipe na estratégia saúde da família. Rev Epidemiol Control Infect [Internet]. 2015 [acesso em 10 abr 20I8];5(I): 3I-36. Disponível em: https://online.unisc.br/seer/index.php/epidemiologia/article/ view/53 I 4 doi: http://dx.doi.org/10.17058/reci.v5il.53|4.

12. Navarro ASS, Guimarães RLS, Garanhani ML. Trabalho em equipe: o significado atribuído por profissionais da estratégia de saúde da família. Rev Min Enferm [Internet]. 2013 [acesso em 3 dez 2017]; I7(I): 6I-68. Disponível em: http:// www.reme.org.br/artigo/detalhes/579 doi: http://www.dx. doi.org/I0.5935//4I5-2762.20I30006.

I3. De Quadros JS, Colomé JS. Metodologias de ensino-aprendizagem na formação do enfermeiro. Rev. baiana enferm [Internet]. 2016 [acesso em 10 mai 20I8];30(2): I- I0. Disponível em: https://portalseer.ufba.br/index.php/enfermagem/ article/view/I5662/pdf_43 doi: http://dx.doi.org//0.1847I/ rbe.v30i2.15662.

14. Braga LM, Torres LM, Ferreira VM. Condições de trabalho e fazer em enfermagem. REV.Enf-UFJF [Internet]. 2015 [acesso em 22 abr 20I8]; I(I): 55-63. Disponível em: https://periodicos.ufjf.br/index.php/enfermagem/article/view/3788.

I5. Barros MEB, Roza MMR, Guedes CR, Oliveira GN. O apoio institucional como dispositivo para a implantação do acoIhimento nos serviços de saúde. Interface (Botucatu) [Internet]. 2014 [acesso em I5 abr 2018]; I8 (Supl I):II0717. Disponível em: http://www.scielo.br/scielo.php?pi$\mathrm{d}=\mathrm{S}|4|$ 4-328320 | $400050 \mid$ | 07\&script=sci_abstract\&tlng=pt doi: http://dx.doi.org//0.1590//807-576220/3.0238.

Recebido: 2020-05-02

Aceito: 2020-08-13 